\title{
In Search of the perfect DROP: Balancing competing interests to achieve optimal design \\ Received: 3rd March, 2005
}

\section{Joseph J. Jankowski}

is an attorney, former adjunct law professor, and pension consultant with over 25 years' experience in the US retirement plan and financial services industry. His particular area of expertise is the public sector, and he currently serves as Executive Director of the State of West Virginia Consolidated Public Retirement Board that administers one defined contribution and six state-wide defined benefit pension plans.

\begin{abstract}
The deferred retirement option plan (DROP) has been the source of much interest and controversy in the US governmental arena over the last twenty years. Uniquely suited for the public sector, ${ }^{1}$ the DROP allows an employee to 'retire' from the pension system, continue to work and collect what would otherwise be his pension in a separate accumulation account. Thus, a DROP arrangement forms a unique 'hybrid' between the traditional defined benefit (DB) pension annuity and the defined contribution (DC) retirement account. This paper explains the basic operation of the DROP, examines the public policy considerations surrounding it, and suggests an optimal design which best suits both the government employee and the taxpaying public.
\end{abstract}

Keywords: deferred retirement option plan (DROP); benefit actuarial calculated (BAC) $D R O P$; defined benefit $(D B)$ pension plan; defined contribution $(D C)$ pension plan; cost-of-living adjustment (COLA); actuarial neutrality; disability pension

Joseph J. Jankowski WV Consolidated Public Retirement Board, 1900 Kanawha Blvd, Capitol Complex, Building 5, Suite 1000, Charleston WV 25305, USA.

Tel: +1 304558 3570; Fax: +1 304558 6337; e-mail: jjankowski@ wvretirement.com

\section{Origin of the DROP}

The DROP originated in East Baton Rouge Parrish, Louisiana in the early 1980s to address a problem caused by the relatively early retirements of public safety personnel. The defined benefit (DB) pension plan design allowed police officers and firemen to collect a full retirement annuity after only 20 years of service. Most participants who were eligible retired as soon as possible, many continuing their professional careers in other jurisdictions. This situation had two detrimental results: (1) the continual need to replace officers imposed heavy recruitment and training costs upon the parrish, and (2) the retired officers, having a long retirement in front of them, demanded cost-of-living adjustments (COLA) to keep up with the rampant inflation during that period.

An enterprising actuary devised a novel solution: the DROP. Officers were allowed, if they so chose, to retire from the pension system, but continue working in the same positions. Although these participants could accrue no more pension benefits, the monthly annuity that they would have earned had they actually retired, was credited to a separate (actually a paper or notational) account, where it accumulated and 
earned interest until the participant actually retired from the parrish. At that time, the officer would be entitled to his normal pension annuity and a considerable lump-sum distribution, often used for a 'bass boat,' recreational motor vehicle, holiday home or some other seemingly desirable high-priced item associated with cessation of working and entry into the time-plentiful world of retirement.

The DROP proved exceedingly popular with employees. They could continue working at their regular job, and build up a substantial account that would be available to them at retirement, ${ }^{2}$ in addition to collecting their regular pension annuity. The employer benefited as well, keeping useful, experienced employees and saving training and replacement costs.

The DROP rapidly spread to teachers and general service governmental workers, and to other jurisdictions including state-level plans. In the succeeding 20 years, about one-half of the 50 states now have some form of DROP programme, along with many larger municipalities as well.

\section{DROP mechanics}

The basic DROP described above (called forward or traditional DROP) is not a separate, qualified retirement plan at all, ${ }^{3}$ but simply a distribution option under a traditional DB plan. A simple illustration may be helpful in allowing the reader to understand the operation of forward DROP:

Police Lieutenant A has 25 years of service with City X, and final average compensation (FAC) of $\$ 70,000$. Under City X's police pension plan, he could retire with a pension of 2 per cent $\mathrm{x}$ FAC $\mathrm{x}$ years of service, or an annual pension equivalent to $\$ 35,000$. Instead of retiring, he decides to go into the DROP programme for five years. At the end of that period he actually retires, begins to collect his pension of $\$ 35,000$ per year (almost \$3,000 per month) and has a lump-sum of $\$ 175,000$ (plus or minus earnings or interest). ${ }^{4}$

Typically, but not always (as explained under actuarial neutrality below), when a participant enters a DROP programme, his mandatory contributions to the pension plan cease, since he is accruing no additional benefits. This has the effect of giving the DROP participant an increase in take home pay and an opportunity to take advantage of personal savings programmes or pre-tax deferred compensation plans, such as those provided under Internal Revenue Code Section 457. Generally, the employer's corresponding contribution will also stop, unless an actuarial under-funding of the DB plan as a whole would require continued annual contributions.

In addition to the basic workings, there are many other considerations in designing a DROP programme, the most salient are as follows.

\section{Drop period}

Most DROPs have a limited period in which a participant, after making the election, can remain in the programme. Three to five years is the most common, but some DROPs have a longer time frame - some are even unlimited. The rationale for the limitation is that to be eligible for DROP, a participant has to be eligible for an unreduced pension, and most employers do not want superannuated employees to continue working indefinitely.

Generally, once a participant enters the DROP programme, he does not have to remain for the maximum allowable period and can actually retire at any time. Some employers, however, impose penalties of some type, usually a 
reduction of credited interest, if a participant does not stay employed for a certain required time. ${ }^{5}$

\section{Interest credited to the DROP account}

Basically, there are three methods by which earnings are attributed to the DROP account:

- Fixed: Here the participant receives a guaranteed amount, usually the same or less than the actuarial assumed rate used for the valuation of the DB pension plan

- Floating: The participant receives a proportionate amount equal to the actual earnings of the trust for the plan year. This can be either a positive or negative amount. Thus, the final amount of the DROP account can fluctuate considerably.

- Self-directed: The trustees select an array of investments, typically stock and bond mutual funds, fixed or stable value funds or guaranteed investment contracts, and the participants select how they want to invest their funds, exactly as in a self-directed DC plan. The participants are completely responsible for their own investment success, or lack thereof.

\section{Availability of disability retirement}

This is often a contentious issue in the design of a DROP programme. Many DROPs simply do not allow disability retirement, feeling that DROP participants have in effect, 'retired,' so there is no need for such a provision. Others, realising the tax advantages in certain types of disability retirement, ${ }^{6}$ provide for a revocation of the DROP election or a reduction of the disability retirement annuity by the value of the DROP account.

\section{Distributions options}

Many of the older, traditional DROP programmes made distributions only in a lump sum. Most new designs allow for a variety of distribution options from which the participant can choose, including delayed distribution, periodic distributions from the trust, joint and survivor annuities, rollover to an Individual Retirement Arrangement (IRA) or some combination of the various options offered.

\section{The mathematics of DROP}

The decision facing a potential DROP participant can often be daunting. In order to obtain the lump sum DROP account, a participant usually must accept a significantly smaller pension annuity.

For example, let us return to the example of Police Lieutenant A, above. If he chose not to enter a DROP, but to work another five years in the pension plan, and assuming annual salary increases of 3 per cent, he would have FAC of about $\$ 81,000$. Now, with 30 years of service, his annual pension at actual retirement would be slightly over $\$ 48,000(30 \times 2$ per cent $\times \$ 81,000)$. This is slightly more than a 33 per cent increase over the $\$ 35,000$ pension he would have received under the DROP programme.

The essential question at DROP decision time then becomes whether the projected 'value' of the lump-sum DROP account $(\$ 175,000$ plus or minus earnings) is greater or less than the projected $\$ 13,000$ annual pension increase? The answer depends upon the individual needs and preferences of Police Lieutenant A. If he likes to manage his own money, have the flexibility and transferability of the DROP account, and is optimistic about the future of financial markets, he will probably choose to enter a DROP. If he 
simply wants the security of a larger guaranteed pension for himself and his spouse, he will probably forego the DROP election.

In any event, potential forward DROP participants need significant financial counselling with the indispensable assistance of a fairly sophisticated computer modelling programme which can project and compare all the variable scenarios available either under a DROP or by remaining in the $\mathrm{DB}$ pension plan.

\section{BAC-DROP - The easier alternative}

From the description above, it is obvious that while traditional or forward DROP can be very advantageous, it is by no means simple. Accordingly, a less complex method called BAC (Benefit Actuarially Calculated) - DROP was devised. BAC-DROP allows a participant to delay the decision to enter DROP until the actual date of retirement. Then, if the employee chooses DROP, his pension will be modified and he will receive a lump sum retroactively, as if he had entered the programme in an earlier year.

By way of illustration, let us take the case of our now familiar Police

Lieutenant A. At his retirement after 30 years of service he can choose his regular pension of $\$ 48,000$ per annum, or he can elect to go back up to the maximum numbers of years stated in the plan (again, usually three to five) and have his pension and lump sum determined as if he had entered the DROP programme at an earlier date. For example, if he elected to 'BAC-DROP' the full five years to when he was first eligible, he would receive the same pension and lump sum first mentioned above: $\$ 35,000$ per year and a lump sum of $\$ 175,000$ (plus or minus earnings). In most BAC-DROP arrangements he would also be entitled to a refund of his contributions made in the last five years to the DB pension plan, along with a stated interest amount.

BAC-DROP has many advantages. It does not require the same sophisticated financial modelling as does forward DROP. The employee takes no risk if there is a floating interest rate, or a self-directed investment option. By choosing the number of years he wishes to BAC-DROP, (from one to five in our example) the employee can, to a large degree, tailor his pension and his lump sum distribution. Additionally, disability retirement becomes a non-issue.

From the employer's perspective, perhaps the only disadvantage of BAC-DROP is that surprise retirements can easily occur. If an employee works beyond normal retirement age, he can elect to BAC-DROP at almost any time, without warning. By contrast, in forward DROP, once an employee is in the programme, his employer knows that he could retire at any time, but will probably stay in for the duration to maximise his lump sum - ostensibly, the reason for entering DROP in the first place. Replacement planning is slightly more difficult for the employer with a BAC-DROP programme.

To make DROP programmes even more complex, some jurisdictions offer their employees a choice of either forward or BAC-DROP, and a few allow the option to choose both. This variation, called 'Combination DROP' is exceedingly detailed and a thorough explanation is beyond the intended limits of this paper.

\section{DROP perspectives: Participant, employer and taxpayers}

\section{The employees' view}

DROPs have proven to be quite popular with governmental employees. A well 
designed programme can be expected to attract upwards of 75 per cent of the eligible participants. ${ }^{8}$

Developing a 'well-designed' programme is the crux of the matter, however, and what the employees may perceive as a good programme may, conversely, be viewed by the employer or the public as too costly or unnecessarily generous.

There is little question that DROP programmes are employee-driven. The flexibility of the hybrid approach and the lure of the large lump sum cause DROP programmes to continually be the subject of labour negotiations or intense lobbying of employee-friendly state and local legislators. Needless to say, employees favour longer DROP periods, generous guaranteed interest rates, COLA adjustments during the programme, a wide variety of distribution options, and the continued availability of disability retirement.

\section{The employer's dilemma}

Public employers want to have satisfied employees, but, of course, they do not want to pay too much for the privilege. In the case of DROP programmes, employers must view their feasibility from two viewpoints: that of costs to the $\mathrm{DB}$ pension system, and the advantages or disadvantages to other cost components of the governmental balance sheet.

Key to the cost assessment process in the pension plan is the concept of actuarial neutrality. This means that DROP programmes are acceptable if they do not cost the system any more in the way of projected future annual contributions. While complex, the issue of cost to the pension system can be somewhat simplified by determining or projecting what impact a DROP programme may have on the average employee retirement age.
For example, if employees are eligible to retire after 25 years of service, but experience studies indicate that the average employee retires after 28 years of service, the plan's actuary will probably assume that the average pension will commence after 28 years. If a DROP programme is instituted which allows participation after 25 years, and the majority of eligible employees enter, the pension system will have to start paying out at an earlier than anticipated time, meaning less time for trust assets to compound, resulting in a cost (and corresponding employer contribution) increase.

Actuarial neutrality is more of a state of utopia than reality, since the true cost of DROP cannot be known until after a programme has been in existence for several years - long enough for actual experience to be sufficient upon which to base future actuarial assumptions and cost predictions. That is the reason that many DROP programmes are initiated on a temporary or experimental basis, with legislatures determining the continued feasibility of the programmes after several years of actual experience.

Often governmental employers attempt to project the cost impact of a pending DROP programme and attempt to achieve the nebulous state of actuarial neutrality by using one or more of the following common techniques:

- The haircut: Here, the employee's DROP account is credited with less than 100 per cent of his earned pension, thus reducing the potential lump-sum payment. A reduction of 15-25 per cent is not out or the ordinary. Upon conclusion of DROP, the participant will receive his full pension annuity.

- The low-interest guarantee: Here, the pension will credit DROP accounts with earnings which are considerably 
less than what the trust expects to actually make. For example, if the actuarial assumed rate of return is 7.5 per cent, DROP participant accounts will be credited with 4 per cent.

- The contribution continuation: Instead of participants ceasing to contribute to the DB pension plan, they will contribute at their same or reduced rate to derive funds that the system expects to lose because of the DROP programme.

- The eligible-age rollback: In order to prevent funds from being paid out earlier than expected, the age and service requirements to be eligible for DROP are pushed back from normal retirement to conform more closely to what the plan's actuary anticipates regular experience would be without a DROP programme.

Counterbalancing the cost issues to the pension system itself are the cost or savings impacts that a DROP programme may have on other areas of government expenditure. For instance, DROP may cause employees to stay on the job longer, thereby decreasing recruitment and training costs. Health and medical costs are significant as well. If an employee remains on the job in DROP, instead of retiring, the government has to cover only one active employee rather than a retiree (generally more expensive) and his replacement.

It is submitted, that the true cost of DROP must be determined from a total governmental perspective rather than focusing simply on the financial impact of the pension system alone.

\section{Public criticism}

DROP programmes have recently been the subject of much negative publicity in the USA. Funding woes caused by the steep stock market decline from
2001-2003, coupled with generous benefit increases passed by legislatures during the funding-rich late 1990s, often have been erroneously attributed, in part at least, to costly DROP programmes.

An unsophisticated press and taxpayer advocate groups often see DROP participants as 'double-dipping' working for a salary and collecting a pension benefit (albeit in an untouchable DC-like account) at the same time. These critics think that it is outrageous that public servants can retire on a pension (often reduced by as much as 30 per cent had one foregone DROP) and a lump sum of several hundred thousand dollars. Since these benefits, as the argument goes, are clearly exorbitant, the tax-paying public must, of necessity, be footing the bill.

\section{The DROP secret}

Unfortunately, the DROP antagonists do not comprehend that it is not the stripping of public coffers that make DROP programmes attractive and beneficial, but rather it is the US government, through the provisions of the Internal Revenue Code. ${ }^{9}$ The powerful financial results of DROP are really caused by the ability of the DROP account to build up tax free over a significant period of time - often five years or longer.

After all, if a governmental employee retired and went to work at another job, earning what he was making previously, he could bank his entire pension, and no one would complain about double-dipping or other irregularities. His savings, however, would be seriously eroded by federal, state, and local income taxes. The DROP participant is really no different, except that his pension deposits build up tax free, resulting in a substantially enhanced lump-sum. 


\section{Conclusion: The perfect DROP}

DROPs are a really good innovation. They combine the security of the traditional DB pension annuity with the portability and flexibility of the DC retirement account. More importantly, though, they afford public servants (who are generally compensated significantly less than their private sector peers) the opportunity to achieve significant wealth-building.

In the author's opinion, the optimal DROP design would possess the following characteristics for the stated reasons:

- Be a forward or traditional programme: While BAC-DROP is appealing in its simplicity, it does not have the upside potential of a forward DROP that has a floating interest rate or is self-directed. Additionally, employers can plan for personnel needs better with a forward design.

- Be Self-Directed: When the participants choose their own investments, they are more involved in their own retirement planning, and the trust is removed from any liabilities for interest guarantees. Additionally, self-direction gives the appearance of removing the DROP assets from the trust, thus placating critics who may feel the public is at risk for earnings promises.

- Use the age rollback or continued contribution method to achieve actuarial neutrality: The 'haircut' and low interest guarantee methods simply are not palatable to employees. Having less than one actually earned being deposited into the DROP account, or receiving a meagre interest rate could quite easily dampen the enthusiasm for the programme.

- Treat the DROP participants like retirees: This means that disability retirement should not be available and COLAs should be applied to DROP accounts just as if the participants had actually retired.

- Be limited to a five-year period: There really can be 'too much of a good thing' and DROP accounts approaching half-a-million dollars being accumulated by participants with 'never-ending employment' may not survive public scrutiny.

\section{References and notes}

1 A DROP programme would probably be discriminatory under Internal Revenue Code (IRC) Section 401(a), but governmental plans are exempt from these requirements.

2 Distributions can generally be rolled over to an IRA under IRC Sections 408 and 72 .

3 A DROP is best described as an arrangement under IRC Section 414(k).

4 The lump-sum total would increase if retiree COLAs were applied.

5 Mandatory retirement issues are frequently the subject of contract law or federal statutes such as the Age Discrimination in Employment Act (ADEA).

6 Under IRC Section 105, certain disability arrangements in the nature of sickness or workers compensation reimbursements may be exempt from federal income taxes.

7 IRC Sections 401(a)(9) and 415.

8 Based upon the author's personal experience with dozens of DROP programmes.

9 IRC Section 401(a). 